\title{
Modulation of the Cholesterol-Dependent Activity of Macrophages IC-21 by CRAC Peptides with Substituted Motif-Forming Amino Acids
}

\author{
A. Ya. Dunina-Barkovskaya ${ }^{a, *}$ and Kh. S. Vishnyakova ${ }^{b}$ \\ ${ }^{a}$ Belozersky Institute of Physico-chemical Biology, Moscow Lomonosov State University, Moscow, 119992 Russia \\ ${ }^{b}$ Engelgardt Institute of Molecular Biology, Russian Academy of Sciences, Moscow, 119191 Russia \\ *e-mail:dunina@belozersky.msu.ru \\ Received May 17, 2020; revised May 28, 2020; accepted May 29, 2020
}

\begin{abstract}
The activity of many membrane proteins, such as receptors, ionic channels, transporters, and enzymes, is cholesterol dependent; however, mechanisms of the cholesterol-dependent regulation of protein functions remain obscure. Recent studies suggest that membrane proteins can directly interact with cholesterol owing to the presence of the cholesterol-recognizing amino-acid consensus (CRAC) motifs. One of the ways to verify and further develop this notion is a design of CRAC-containing peptides and investigation of their effects on cholesterol-dependent cell functions. Previously we showed that a newly constructed peptide RTKLWEMLVELGNMDKAVKLWRKLKR (peptide P4) containing two CRAC motifs modulates cholesteroldependent interactions of cultured macrophages IC-21 with $2-\mu \mathrm{m}$ particles. In this work, in order to clarify the role of CRAC-forming amino acids, we employed the same experimental system to test the activity of peptides closely related to P4 but with modified CRAC motifs. We found that peptide STKLSEMLSELGNMDKASKLSRKLSR (Mut2) analogous to P4, except that all CRAC-forming amino acids (V, W, K/R) were substituted by serine, did not produce any effect in the concentration range $0.5-50 \mu \mathrm{M}$ corresponding to the range of the P4 activity. Neither was effective peptide RTKLSEMLVELGNMDKAVKLSRKLKR (Mut3), in which only aromatic amino acids (W) of the CRAC motifs were substituted. Peptide STKLWEMLVELGNMDKAVKLWRKLSR (Mut4), in which only cationic amino acids $(\mathrm{R} / \mathrm{K})$ in the CRAC motifs were changed, produced almost the same effect as that of peptide P4 with a bell-shape dose-response curve. At low concentrations $(1-4 \mu \mathrm{M})$ Mut 4 notably increased the number of beads per cell, at higher concentrations this parameter diminished, and at $50 \mu \mathrm{M}$ Mut4 produced a robust toxic effect. Finally, peptide EWGMAVLWERNRKLKKDLKVLKMLRT (Mut1) composed of the same amino acid residues as P4 but in a random order ("scramble") and possessing one CRAC motif, different from that in P4, produced a moderate stimulation at $4-10 \mu \mathrm{M}$ but was not toxic at $50 \mu \mathrm{M}$. As in the case of peptide P4, the effects of Mut4 and Mut 1 depended on the cholesterol content in the cell membrane: after the incubation of cells with cholesterol-extracting agent methyl- $\beta$-cyclodextrin stimulatory effects produced by Mut4 and Mut 1 at low doses were suppressed. Our results indicate that CRAC motifs play an important role in the mechanisms of the peptide-induced modulations of cholesterol-dependent cell functions in the experimental system used and that of the three motif-forming amino acids, critical is the presence of the aromatic amino acid (W). Further research is required to comprehend the molecular mechanisms of interactions of CRAC-containing peptides with cell membrane components that lead to modulation of cell functions. We anticipate that CRAC-containing peptides may provide a basis for the development of new tools for directed regulation of the activity of target cholesterol-dependent membrane proteins and for the design of new antimicrobial and immunomodulating drugs in particular.
\end{abstract}

Keywords: peptides, cholesterol, cholesterol-recognizing aminoacid consensus, CRAC-motif, influenza virus protein M1, methyl- $\beta$-cyclodextrin, macrophages, phagocytosis, adhesion

DOI: $10.1134 / \mathrm{S} 1990747820040054$

\section{INTRODUCTION}

The activity of many membrane proteins - receptors, ion channels, transporters and enzymes - is cholesterol-dependent [1-7]. Impairments in the distribution, transport, and metabolism of cholesterol play an essential role in the pathogenesis of atherosclerosis [2, 8], AIDS [9], as well as Alzheimer's [10], Nie-
mann-Pick [11], Charcotte-Marie-Tooth [12], and many other diseases. Moreover, cholesterol-dependent processes play a key role in the development of many infectious diseases, since the interaction of the pathogen with the host cell in many cases occurs with the participation of cholesterol. For example, the entry of certain viruses $[9,13-15]$ and bacteria [16$20]$ into the cell depends on the presence of cholesterol 
and lipid rafts $[15,16,21]$ in the membranes of the host cells. Understanding the molecular mechanisms of protein-cholesterol interactions and their role in cellular processes can provide the basis for the development of new methods for the prevention and treatment of such diseases.

In 1998, Li and Papadopolous [22] showed that mitochondrial cholesterol-transporting protein BPR (a peripheral type benzodiazepine receptor, later renamed the translocator protein, TSPO [23]) contains a domain with amino-acid sequence ATVLNYYVWRDNS, which is critical for binding and transport of cholesterol. The authors also found that similar domains containing cationic $(\mathrm{R} / \mathrm{K})$, aromatic $(\mathrm{Y})$, and nonpo$\operatorname{lar}(\mathrm{V} / \mathrm{L} / \mathrm{I})$ amino-acid residues in a certain order exist in other cellular proteins that interact with cholesterol. The authors called this region "cholesterol-recognizing amino-acid consensus" (CRAC) and proposed a general formula of the CRAC motif: L/V- $(\mathrm{X})_{(1-5)}-\mathrm{Y}-$ $(X)_{(1-5)}-\mathrm{R} / \mathrm{K}$ [22]. Later this concept was examined and refined in the course of numerous experimental and theoretical studies (reviews [24, 25]).

One way to test and develop the idea of cholesterolrecognizing sequences in cell proteins is a design CRAC-containing peptides and a study of their effect on cholesterol-dependent cellular functions. If this concept is correct, then CRAC-containing peptides can serve as a useful tool not only for research but also for the regulation of cholesterol-dependent processes in cells. The possibility of such regulation in vitro was directly demonstrated in 2001 by the authors of the CRAC concept [26].

Earlier, we showed that a new peptide RTKLWEMLVELGNMDKAVKLWRKLKR (hereinafter P4), constructed from two CRAC-containing peptides corresponding to $\alpha$-helices 3 and 6 of the influenza virus M1 protein, dose-dependently modulates cholesterol-dependent interactions of cultured macrophages IC-21 with $2-\mu \mathrm{m}$ particles $[27,28]$. In this work, in order to determine the role of CRAC motifs and motif-forming amino acids in the observed effects of $\mathrm{P} 4$, we constructed mutant peptides corresponding to P4 in amino acid composition, but with modified CRAC motifs, and investigated the effects of the new peptides in the same experimental system. We found that: (1) mutant peptide Mut2 with substitutions of all motif-forming amino acids with serine $(\mathrm{V} \rightarrow \mathrm{S} ; \mathrm{W} \rightarrow \mathrm{S}$; $\mathrm{R} / \mathrm{K} \rightarrow \mathrm{S}$ ) did not significantly affect the interactions of macrophages IC-21 with particles; (2) peptide Mut3, in which only aromatic amino acids were replaced in both CRAC motifs (W $\rightarrow \mathrm{S}$ ), did not affect the cell activity, either; (3) the effects of peptide Mut4 with substitutions of only cationic amino acids in both CRAC motifs $(\mathrm{R} / \mathrm{K} \rightarrow \mathrm{S})$ scarcely differed from the effects of the parental peptide P4: at low concentrations $(1-4 \mu \mathrm{M})$, Mut4 stimulated the cell activity and at high concentrations $(\sim 50 \mu \mathrm{M})$ produced a toxic effect; (4) peptide Mut1 composed of the same amino acids as $\mathrm{P} 4$ but in a random order ("scramble") and having one CRAC motif, which was formed incidentally and differed from the CRAC motifs present in peptide $\mathrm{P} 4$, exerted a moderate stimulating effect at 4$10 \mu \mathrm{M}$ and was not toxic at $50 \mu \mathrm{M}$; (5) pretreatment of cells with methyl- $\beta$-cyclodextrin extracting membrane cholesterol weakened the stimulatory effects of peptides Mut4 and Mut1. The obtained data indicate that CRAC motifs play an essential role in the mechanism of the peptide P4-induced modulation of the cholesterol-dependent cell activity and that the presence of aromatic amino acids in the motif is critical for the peptide effects.

\section{MATERIALS AND METHODS}

Peptides. The following peptides were used in this work (Table 1): Ac-RTKLWEMLVELGNMDKAVKLWRKLKR- $\mathrm{NH}_{2}$ (peptide $\mathrm{P} 4,26$ amino-acid residues, mol. mass (MM) $3764 \mathrm{Da}$; hereinafter CRAC motifs are underlined and motif-forming amino acids and their substitutions are shown in bold), Ac-STKLSEMLSELGNMDKASKLSRKLSR-NH ${ }_{2}$ (Mut2, $M M 3434 \mathrm{Da} ; 5,21 \mathrm{~W} \rightarrow \mathrm{S} ; 9,18 \mathrm{~V} \rightarrow \mathrm{S} ; 1 \mathrm{R}, 25 \mathrm{~K} \rightarrow \mathrm{S})$, Ac-RTKLSEMLVELGNMDKAVKLSRKLKR-NH (Mut3, MM $3525 \mathrm{Da} ; 5,21 \mathrm{~W} \rightarrow \mathrm{S}$ ), Ac-STKLWEMLVELGNMDKAVKLWRKLSR-NH ${ }_{2}$, (Mut4, $M M \sim 3654 \mathrm{Da} ; 1 \mathrm{R}, 25 \mathrm{~K} \rightarrow \mathrm{S}$ ), and Ac-EWGMAVLWERNRKLKKDLKVLKMLRT-NH 2 (Mut1, $M M \sim 3764 \mathrm{Da}$ ). All peptides (purity $\geq 95 \%$ ) were synthesized in Syneuro Co. Ltd., Russia. Peptide P4 ("parental") was constructed earlier on the basis of two $\alpha$-helical CRAC-containing fragments of the M1 protein of the influenza virus [27, 28]. Peptide Mut1 consisted of the same 26 amino acids as P4 but in a random order ("scramble") and contained one incidentally generated CRAC motif, different from the CRAC motifs of peptide P4. In peptides Mut2, Mut3, and Mut4, only CRAC motifs were modified; otherwise, the amino-acid sequence corresponded to that of P4. In Mut2, all motif-forming amino acidsvaline, tryptophan, arginine, and lysine-were replaced by serine in both CRAC motifs $(\mathrm{V} \rightarrow \mathrm{S} ; \mathrm{W} \rightarrow \mathrm{S}$; $\mathrm{R} / \mathrm{K} \rightarrow \mathrm{S}$ ). In Mut3, only aromatic amino acid tryptophan was replaced by serine in both CRAC motifs $(\mathrm{W} \rightarrow \mathrm{S})$. In Mut4, only cationic amino acids arginine and lysine were replaced by serine in both CRAC motifs $(\mathrm{R} / \mathrm{K} \rightarrow \mathrm{S})$. The list of peptides and their main parameters are given in Table 1. For all peptides, the C-terminus is acetylated. In a previous paper [28], we used non-acetylated peptide P4; dose-response curves of the effects of acetylated and non-acetylated versions of $\mathrm{P} 4$ did not differ significantly. Before the experiment, concentrated solutions of peptides (from 0.05 to $5 \mathrm{mM}$ ) in dimethyl sulfoxide (DMSO, MP Biomedicals, France) were prepared. After the addition of the peptide to the incubation medium the final concentration of DMSO did not exceed $1 \%$. 
Table 1. Nomenclature and some parameters of the peptides used in the work

\begin{tabular}{|c|c|c|c|c|}
\hline Peptide & Amino-acid sequence & $\begin{array}{c}M M, \\
\mathrm{Da}\end{array}$ & $\begin{array}{c}\text { Modifications } \\
\text { of CRAC-motifs }\end{array}$ & Peptide features \\
\hline$\overline{\mathrm{P} 4}$ & Ac- $\underline{\text { RTKLWEMLVELGNMDKAVKLWRKLKR-NH }} \mathrm{NH}_{2}$ & 3764 & - & $\begin{array}{l}\text { "Parental" peptide } \\
\text { with two CRAC-motifs [28] }\end{array}$ \\
\hline Mut2 & Ac-STKLSEMLSELGNMDKASKLSRKLSR- $\mathrm{NH}_{2}$ & 3434 & $\begin{array}{c}5,21 \mathrm{~W} \rightarrow \mathrm{S} \\
9,18 \mathrm{~V} \rightarrow \mathrm{S} \\
1 \mathrm{R}, 25 \mathrm{~K} \rightarrow \mathrm{S}\end{array}$ & $\begin{array}{l}\text { The same primary structure } \\
\text { as in P4, but with substitu- } \\
\text { tions of all motif-forming } \\
\text { amino acids in both CRAC } \\
\text { motifs }\end{array}$ \\
\hline Mut3 & Ac-RTKLSEMLVELGNMDKAVKLSRKLKR- $\mathrm{NH}_{2}$ & 3525 & $5,21 \mathrm{~W} \rightarrow \mathrm{S}$ & $\begin{array}{l}\text { The same primary structure } \\
\text { as P4, but with substitutions } \\
\text { of aromatic amino acid (Trp) } \\
\text { in both CRAC motifs }\end{array}$ \\
\hline Mut4 & Ac-STKLWEMLVELGNMDKAVKLWRKLSR- $\mathrm{NH}_{2}$ & 3654 & $\begin{array}{c}\mathrm{R} / \mathrm{K} \rightarrow \mathrm{S} \\
1 \mathrm{R}, 25 \mathrm{~K} \rightarrow \mathrm{S}\end{array}$ & $\begin{array}{l}\text { The same primary structure } \\
\text { as in P4, but with substitu- } \\
\text { tions of cationic amino } \\
\text { acids (Arg, Lys) } \\
\text { in both CRAC motifs }\end{array}$ \\
\hline Mut1 & Ac-EWGMAVLWERNRKLKKDLKVLKMLRT- $\mathrm{NH}_{2}$ & 3764 & $\begin{array}{l}\text { New CRAC- } \\
\text { motif }\end{array}$ & $\begin{array}{l}\text { The same amino acid } \\
\text { composition as in P4, but in a } \\
\text { random order ("scramble"); } \\
\text { one CRAC motive, different } \\
\text { from the motives in P4 }\end{array}$ \\
\hline
\end{tabular}

All peptides contain 26 amino-acid residues. Underlined are CRAC motifs (both intact and modified). A peptide with the sequence

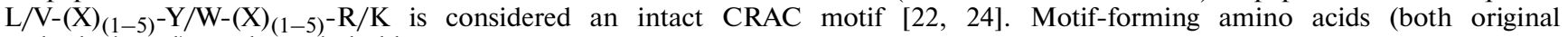
and substituted) are shown in bold type.

Cell culture. Experiments were performed on cultured cells IC-21 (immortalized mouse peritoneal macrophages, ATCC no. TIB-186 $\left.{ }^{\mathrm{TM}}\right)$. The cells were cultured in Dulbecco's modified Eagle medium (DMEM, PanEco, Russia) supplemented with $10 \%$ fetal calf serum (Biolot, Russia), $2 \mathrm{mM} L$-glutamine (PanEco), and 40 Units/mL gentamicin (PanEco) in the atmosphere containing $5 \% \mathrm{CO}_{2}$, at $37^{\circ} \mathrm{C}$. Cells were replated twice a week using Versen's solution (PanEco). Two days before the experiments, the cells were seeded onto 6-well plates (Costar, USA) at a density of $\sim 50000$ cells per well.

Quantification of the peptide effects on the macrophage activity. The activity of macrophages was assessed by their ability to bind non-opsonized latex $2-\mu \mathrm{m}$ particles and was measured as the number of particles associated with the cells ("phagocytic index") according to the protocol described previously [2731] with minor modifications. Cells in 6-well plates were preincubated for $1 \mathrm{~h}$ at $37^{\circ} \mathrm{C}, 5 \% \mathrm{CO}_{2}$ in serumfree DMEM in order to minimize the inhibitory effect of serum on particle adhesion and phagocytosis [30]. In some experiments, methyl- $\beta$-cyclodextrin $(\mathrm{m} \beta \mathrm{CD}$; Sigma, USA) was added to the DMEM during this incubation. After preliminary incubation in serumfree medium, $1 \mathrm{mg} / \mathrm{mL}$ albumin (Sigma) and the studied peptide (from a concentrated solution in
DMSO) in a final concentration of 0.5 to $50 \mu \mathrm{M}$, as well as fluorescent particles (Fluoresbrite Carboxy YG 2.0 Micron Microspheres, Polysciences, Inc., USA) in the amount of $8 \times 10^{6}$ particles per well were added to the cells in the wells. The cells, to which DMSO (0.5-1\%) without peptide was added, served as the control. Cells were incubated at $37^{\circ} \mathrm{C}$ and $5 \% \mathrm{CO}_{2}$ for $1 \mathrm{~h}$, then washed twice with phosphate-buffered saline (PBS) to remove unattached particles and fixed with $2.5 \%$ glutaraldehyde (Ted Pella, USA) solution in PBS.

Cell activity was assessed by the number of particles bound by the cells. Particle adhesion on the surface of the phagocyte precedes phagocytosis, depends on the availability of phagocytic receptors, including integrins, and is a necessary condition for phagocytosis [32-36]. The number of particles per cell was determined according to the procedure described previously [27-31]. Microphotographs of cells were taken in phase contrast and fluorescence mode (excitation/emission $490 / 520$ and $520 / 590 \mathrm{~nm}$ for fluorescence of particles and autofluorescence of glutaraldehyde, respectively) using fluorescent microscope Zeiss Axiovert 200M (Carl Zeiss, Germany niya) equipped with a digital video camera ORCAII-ERG2 (Hamamatsu, Japan) and corresponding software (Axiovision 4.5, Carl Zeiss Imaging). In each well, 
10-20 randomly selected view fields were photographed. Using ImageJ and a specially developed software module [30, 31], the number of particles per cell was determined for each field of view; at least 200 cells were counted in each well. To compare the effects of peptides in different experiments, the number of particles per cell was expressed as a percentage of the control value obtained in a given experiment and taken as $100 \%$. Since the activity of IC-21 cells depends on the density of the culture [31], we used loose cultures ( $\sim 15-60$ cells per a field of view, which corresponds to $\sim 5-20 \%$ of the dense monolayer). Data are presented as mean $\pm \mathrm{SEM}$; the number of independent experiments $(3-8)$ is indicated in the figure captions. The significance of differences between groups was determined using the Student's $t$-test. Statistical and graphical data processing was performed using the built-in programs OriginPro 7.5 (OriginLab Corporation, USA).

\section{RESULTS}

Effects of peptides on the macrophage activity. Under control conditions, the number of particles per cell varied from 1.5 to 4.2 in different experiments and averaged $2.7 \pm 0.2$ (mean $\pm \mathrm{SEM}, n=27)$. Figure 1 illustrates the effect of peptide P4 containing two CRAC motifs (RTKLWEMLVELGNMDKAVKLWRKLKR) on the efficiency of the particle attachment on the cell surface: a representative experiment is shown in Fig. 1a and the dose-effect curve obtained on the basis of 8 independent experiments, in Fig. $1 \mathrm{~b}$. The concentration dependence of the $\mathrm{P} 4$ effect is bellshaped: at $0.5-5 \mu \mathrm{M}$ the number of particles per cell is significantly higher than the control value $(\sim 200 \%$ of the control); at higher concentrations the phagocytic index decreases, and at $20-25 \mu \mathrm{M}$ it is about $50 \%$ of the control (Fig. 1b). At $50 \mu \mathrm{M}$, peptide P4 exerted a clear toxic effect: in all experiments, at this dose of P4, almost all cells died (Fig. 1c).

Mutant peptide Mut2 (STKLSEMLSELGNMDKASKLSRKLSR), in which all motif-forming amino acids in both CRAC motifs were replaced by serine $(\mathrm{V} \rightarrow \mathrm{S} ; \mathrm{W} \rightarrow \mathrm{S} ; \mathrm{R} \rightarrow \mathrm{S})$, did not cause significant changes in the phagocytosis index in the concentration range from 0.5 to $50 \mu \mathrm{M}$ and was not toxic at $50 \mu \mathrm{M}$ (Figs. 2a, 2b). Neither was effective peptide Mut3 (RTKLSEMLVELGNMDKAVKLSRKLKR), in which only aromatic amino acids in both CRAC motifs were replaced by serine $(\mathrm{W} \rightarrow \mathrm{S})$ (Figs. 2c, 2d).

The effects of peptide Mut4 (STKLWEMLVELGNMDKAVKLWRKLSR), in which only cationic amino acids (arginine and lysine) were replaced by serine in both CRAC motifs $(R / K \rightarrow S)$, is illustrated in Fig. 3. As in the case of P4, at low concentrations Mut4 significantly increased the cell activity (up to $\sim 210 \%$ of the control at $1-4 \mu \mathrm{M}$ ); at $\sim 10 \mu \mathrm{M}$ phagocytic index returned to the control level, and at $50 \mu \mathrm{M}$ a toxic effect developed (Fig. 3c); in some experiments, signs of toxic effects were observed at $20 \mu \mathrm{M}$
Mut4. In general, as Fig. 3b shows, the concentration dependencies of the effects of Mut4 and P4 are very much alike.

Mutant peptide Mut1 (EWGMAVLWERNRKLKKDLKVLKMLRT) was created from the same amino acids as the parent peptide $\mathrm{P} 4$, but in a random order ("scramble"). Peptide Mut1 contained one randomly generated CRAC motif (VLWER), which was different from both CRAC motifs of peptide P4 (RTKLWEMLV and VKLWRKLKR). At concentrations of $2-10 \mu \mathrm{M}$, peptide Mut 1 moderately (up to $\sim 160 \%$ of the control) but significantly increased the number of particles per cell; the maximal effect developed at $\sim 4-5 \mu \mathrm{M}$ (Fig. $4 \mathrm{~b}$ ). At higher concentrations of Mut 1 phagocytic index decreased and returned to the control level at $50 \mu \mathrm{M}$ Mut1. In contrast to P4, peptide Mut 1 at $50 \mu \mathrm{M}$ did not exert a toxic effect on the cells (Fig. 4c). Table 2 summarizes the obtained data on the activity of the studied peptides.

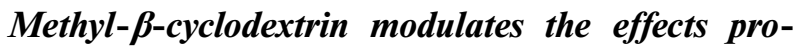
duced by peptides P4, Mut4, and Mut1. We previously showed [28] that methyl- $\beta$-cyclodextrin, which extracts membrane cholesterol [37-40], dosedependently suppresses the simulating effect caused by peptide $\mathrm{P} 4$ at low concentrations and significantly reduces the concentration of the toxic effect of the $\mathrm{P} 4$ peptide [28]. In this work, we found that preliminary incubation of cells in the presence of methyl- $\beta$ cyclodextrin similarly modulates the effects of the peptides Mut4 and Mut1 (Fig. 5). It is important to note that in this work we used low concentrations of $\mathrm{m} \beta \mathrm{CD}(<5 \mathrm{mM})$, at which $\mathrm{m} \beta C D$ itself not only failed to inhibit the cell activity, but also significantly increased it. This phenomenon is described in the literature and can be accounted for by the existence of an optimal concentration of cholesterol in the membrane and activation of the cholesterol-dependent cell functions when "excess" cholesterol is removed from the membranes [19, 41]. In our system, the stimulating effect of $m \beta C D$ at low concentrations can be explained by the redistribution of cholesterol extracted by $\mathrm{m} \beta C D$ [37-39] from cells with a high cholesterol content to the cells with low cholesterol level. Such a redistribution should lead to a decrease in the proportion of poorly functioning cells with "excess" cholesterol and an increase in the proportion of cells having enough cholesterol for the normal functioning of the cholesterol-dependent receptors necessary for the particle binding.

In the experiment presented in Fig. 5a, $2.5 \mu \mathrm{M}$ peptide $\mathrm{P} 4$ causes a typical strong stimulation (second column); $2 \mathrm{mM} \mathrm{m} \beta \mathrm{CD}$ slightly but significantly (by $\sim 20 \%, p<0.05$ ) increases the number of particles per cell as compared with the control (third column); however, the response of the cells treated with $2 \mathrm{mM}$ $\mathrm{m} \beta \mathrm{CD}$ to $2.5 \mu \mathrm{M} \mathrm{P} 4$ (fourth column) is significantly weaker (by $\sim 60 \%, p<0.001$ ) than the response to $2.5 \mu \mathrm{M}$ P4 of the cells not treated with $\mathrm{m} \beta \mathrm{CD}$. A sim- 

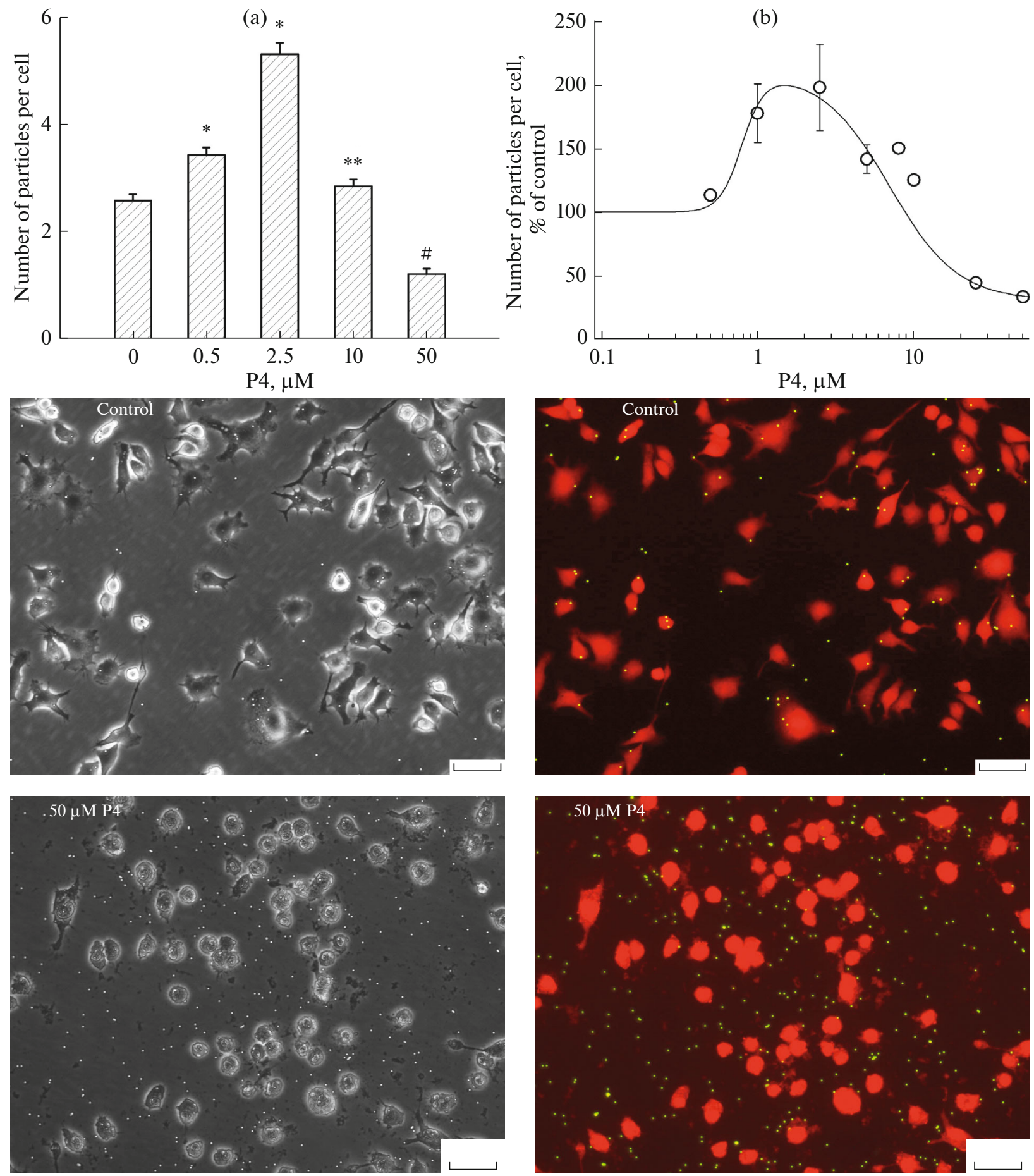

Fig. 1. The effect of peptide P4 (RTKLWEMLVELGNMDKAVKLWRKLKR) on the binding of 2- $\mu$ m non-opsonized particles by cultured IC-21 macrophages. ( $a, b)$ Dose dependence of the effect of peptide P4 on the mean number of particles bound by cells. (a) Representative experiment; each point is a mean number of particles per cell \pm SEM obtained for $\geq 200$ cells per well at a given peptide concentration. (b) Dose-response curve for P4 plotted on the basis of 8 independent experiments; cell activity is expressed as a percentage of the control value in each experiment (control conditions: instead of the peptide, DMSO is added in a corresponding concentration, 0.5 or $1 \%$ DMSO). The difference from the control is significant by the Student's $t$-test at $p<$ $0.001\left(^{*}\right), p<0.05(* *)$, or $p<0.01$ (\#). (c) Microphotographs of the cells illustrating the toxic effect of $50 \mu \mathrm{M}$ P4; left, phase contrast; right, fluorescence mode (green channel, particles; red channel, glutaraldehyde). Scale bar, $50 \mu \mathrm{m}$. 


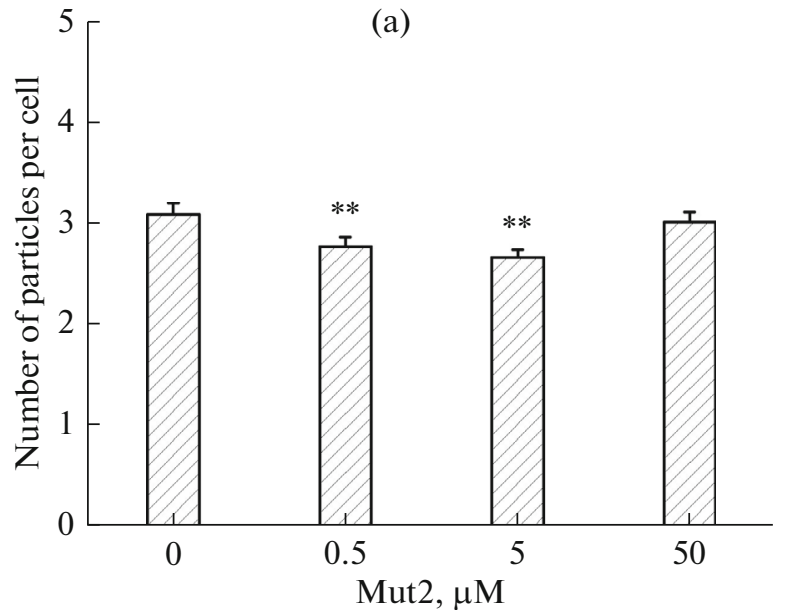

(c)

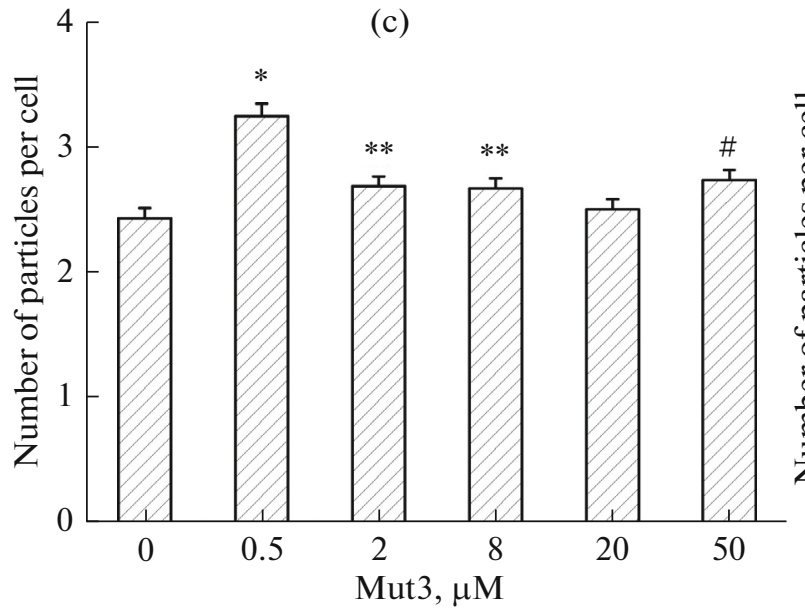

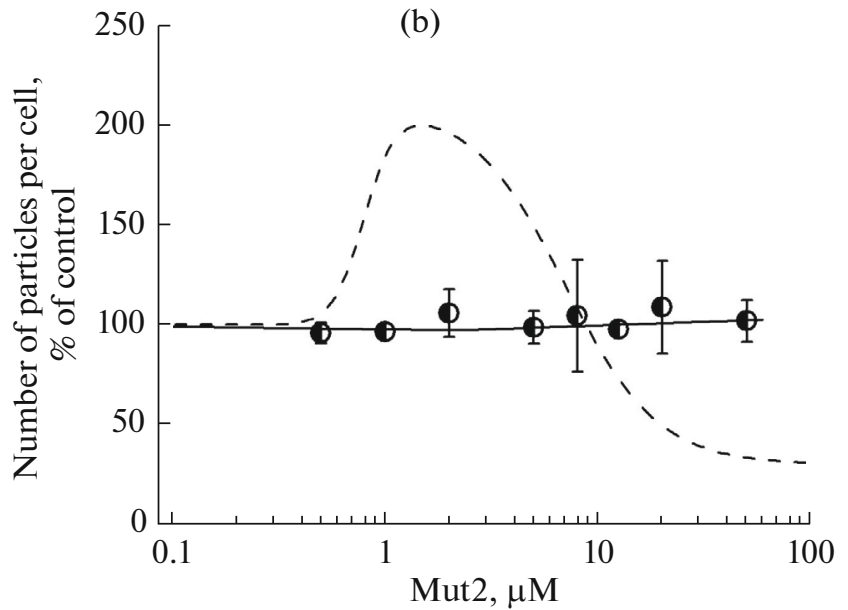

(d)

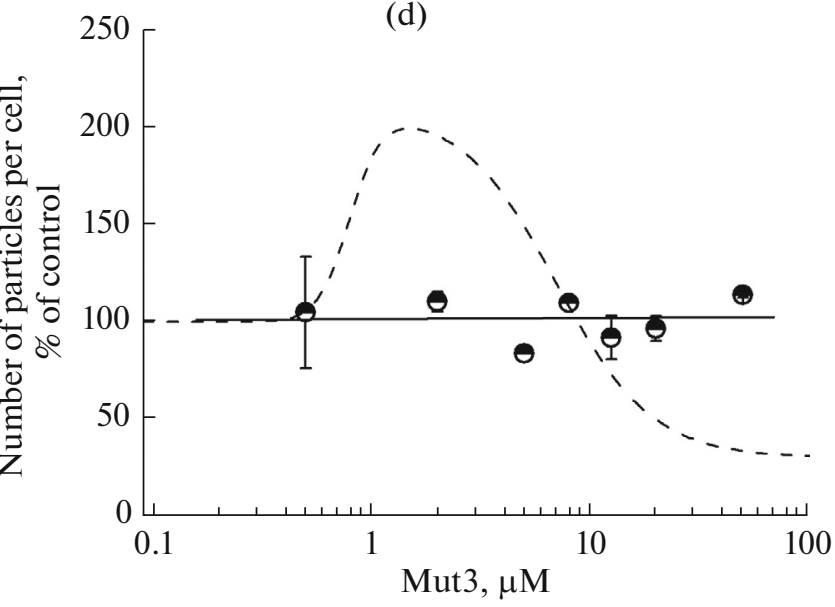

Fig. 2. Mutant peptide Mut2 (STKLSEMLSELGNMDKASKLSRKLSR) with substitutions of all motive-forming amino acids in CRAC motifs $(\mathrm{V} \rightarrow \mathrm{S} ; \mathrm{W} \rightarrow \mathrm{S} ; \mathrm{R} / \mathrm{K} \rightarrow \mathrm{S})(\mathrm{a}, \mathrm{b})$ and mutant peptide Mut3 (RTKLSEMLVELGNMDKAVKLSRKLKRKR) with substitutions of only aromatic amino acids in CRAC motifs $(\mathrm{W} \rightarrow \mathrm{S})(\mathrm{c}, \mathrm{d})$ in the concentration range $0.5-50 \mu \mathrm{M}$ do not cause significant changes in the activity of IC-2 cells. (a, c) Representative experiments; one column shows a mean number of particles per cell \pm SEM obtained for $\geq 200$ cells in a given well; the difference from the control is significant by Student's $t$-test at $p<0.001(*), p<0.05(* *)$, or $p<0.01(\#)$. (b, d) Dose-response curves for Mut2 (b) and Mut3 (d), plotted on the basis of 6 independent experiments for each peptide; cell activity is expressed as a percentage of the control value in each experiment (control conditions: instead of the peptide, DMSO is added in a corresponding concentration, 0.5 or $1 \%$ DMSO). In (b, d) doseresponse curves for peptide $\mathrm{P} 4$ are shown for comparison (dashed lines).

ilar effect was observed in the case of peptides Mut4 (Fig. 5b) and Mut1 (Fig. 5c). At a concentration of $2 \mu \mathrm{M}$, Mut 4 causes a significant increase in the number of particles per cell (up to $\sim 200 \%$ of the control, $p<0.001$; Fig. 5b). But if the peptide was added after incubation of the cells with $2 \mathrm{mM} \mathrm{m} \beta \mathrm{CD}$, the stimulatory effect of $2 \mu \mathrm{M}$ Mut 4 peptide was by $40 \%$ weaker $(p<0.005)$ than in cells not treated with $\mathrm{m} \beta \mathrm{CD}$. In the

Table 2. Effects of the studied peptides in the concentration range from 0.5 to $50 \mu \mathrm{M}$

\begin{tabular}{l|c|c}
\hline \multicolumn{1}{c|}{ Peptide } & Stimulatory effect & Toxic effect \\
\hline P4 (parental) & $\sim 200 \%(1-2 \mu \mathrm{M})^{*}$ & $\sim 50 \mu \mathrm{M}$ \\
Mut1 ("scramble" with one CRAC motif) & $\sim 160 \%(4-10 \mu \mathrm{M})^{*}$ & - \\
Mut2 (substitution of all motif-forming amino acids in two CRAC motifs) & - & - \\
Mut3 (substitution of only aromatic amino acids in two CRAC motifs) & - & - \\
Mut4 (substitution of only cationic amino acids in two CRAC motifs) & $\sim 210 \%(1-4 \mu \mathrm{M})^{*}$ & $20-50 \mu \mathrm{M}$ \\
\hline
\end{tabular}

* Maximal effect produced by the peptide in \% of the control level; in parenthesis is the concentration range, at which maximal effect was observed. 

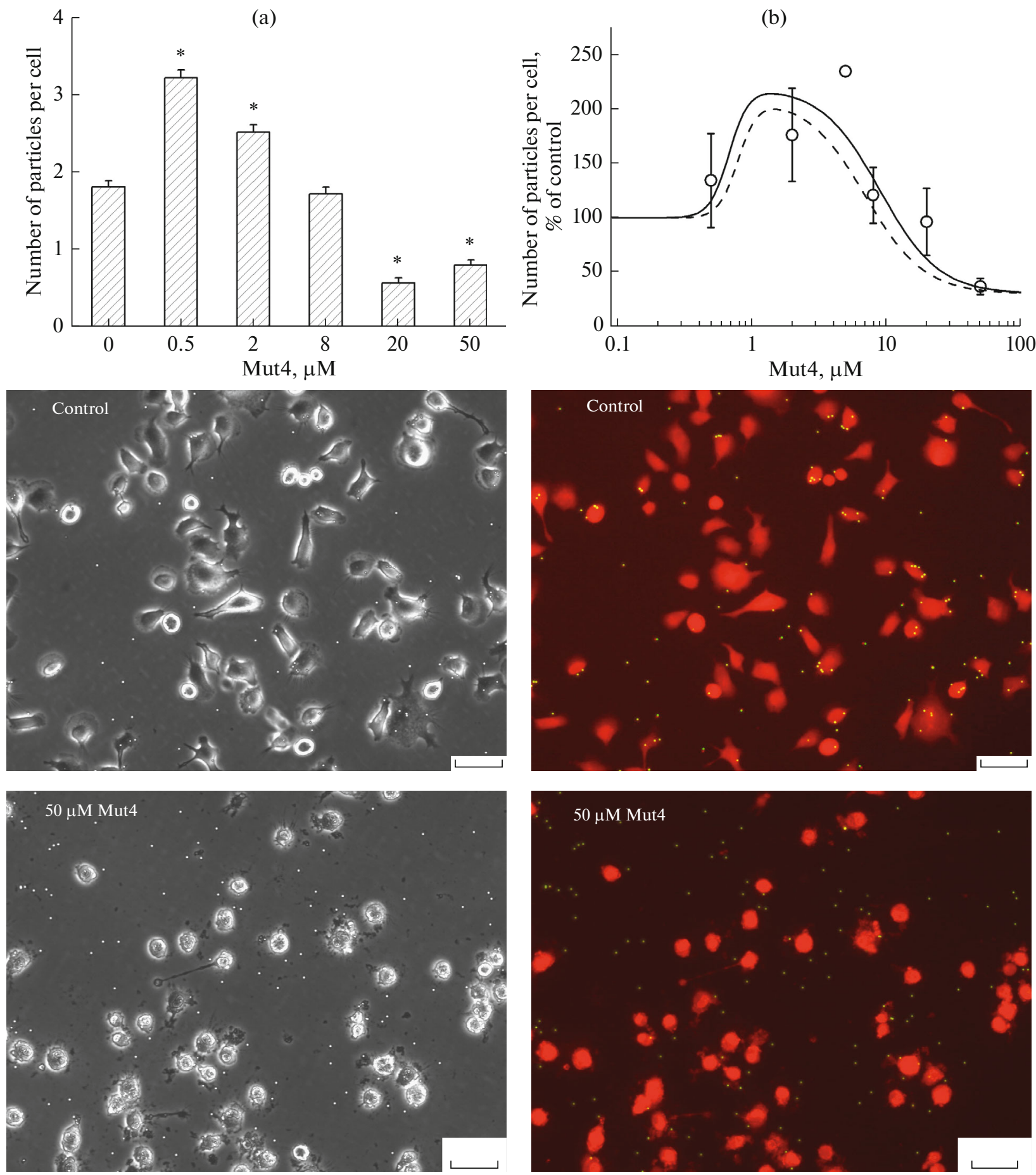

Fig. 3. The effect on the activity of macrophages IC-21 of mutant peptide Mut4 (STKLWEMLVELGNMDKAV KLWRKLSR) with substitutions of only cationic amino acids in both CRAC motifs $(\mathrm{R} / \mathrm{K} \rightarrow \mathrm{S})$ is similar to the effect of peptide P4. (a, b) Dose dependence of the peptide Mut 4 effect on the mean number of particles associated with cells. (a) Representative experiment; each point is a mean number of particles per cell \pm SEM obtained for $\geq 200$ cells per well at a given peptide concentration; the difference from the control is significant by the Student's $t$-test at $p<0.001(*)$. (b) Dose-response curve for Mut4, plotted on the basis of 6 independent experiments; cell activity is expressed as a percentage of the control value in each experiment (control conditions: instead of the peptide, $1 \%$ DMSO is added); for comparison, dose-response curve for peptide P4 is shown (dashed line). (c) Micrographs of the cells illustrating the toxic effect of Mut4; left, phase contrast; right, fluorescence mode (green channel, particles; red channel, glutaraldehyde). Scale bar, $50 \mu \mathrm{m}$. 

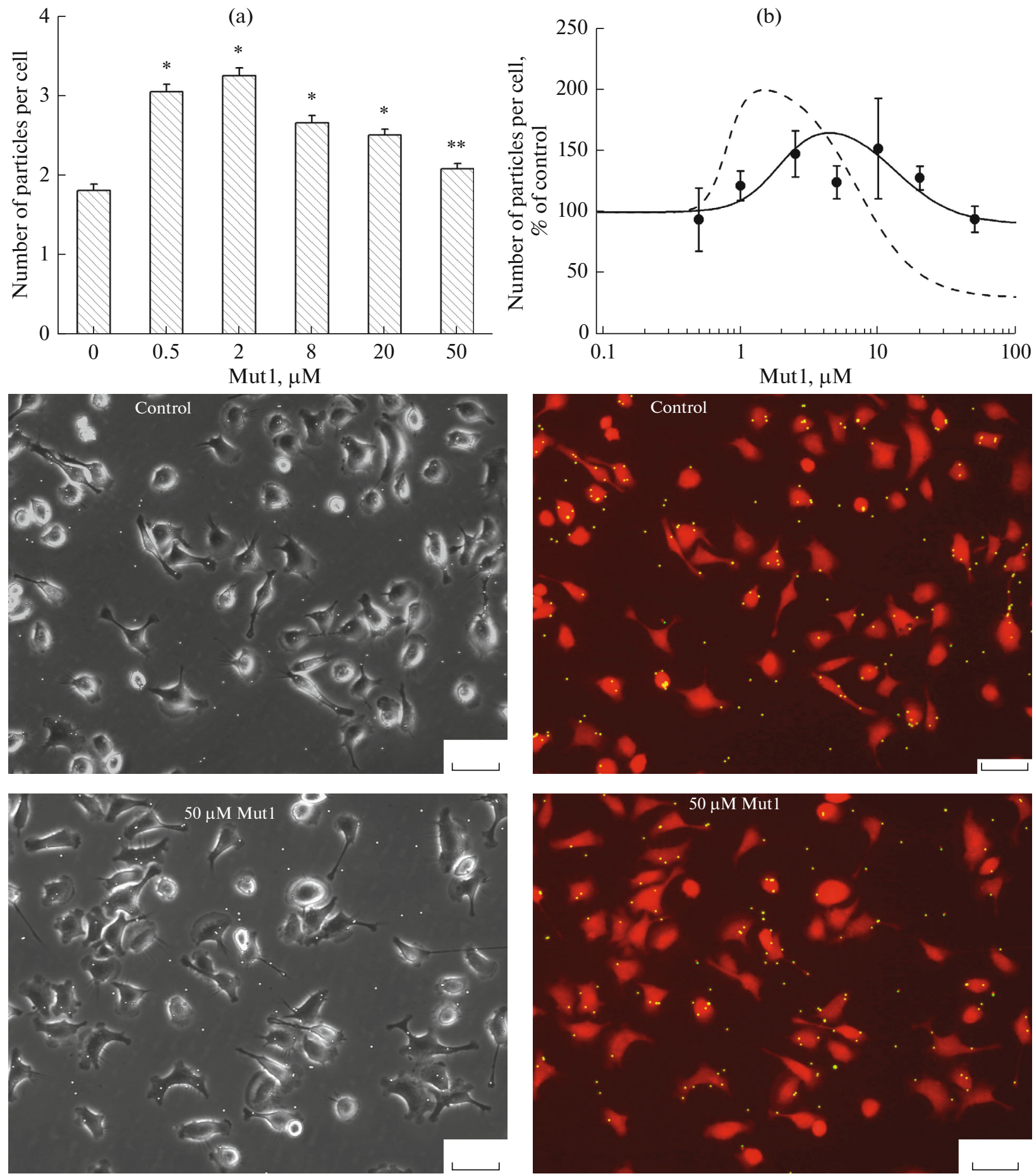

Fig. 4. The effect on the activity of macrophages IC-21 of mutant ("scramble") peptide Mut1 (EWGMAVLWERNRKLKKDL KVLKMLRT). (a) Representative experiment; each point is a mean number of particles per cell \pm SEM obtained for $\geq 200$ cells per well at a given peptide concentration; the difference from the control is significant by the Student's $t$-test at $p<0.001(*)$ or $p<0.05$ (**). (b) Dose-response curve for Mut1, plotted on the basis of 7 independent experiments; cell activity is expressed as a percentage of the control value in each experiment (control conditions: instead of the peptide, $1 \%$ DMSO is added); for comparison, dose-response curve for peptide P4 is shown (dashed line). (c) Microphotographs of cells illustrating the absence of a toxic effect of $50 \mu \mathrm{M}$ Mut 1: upper row, control; lower row, in the presence of $50 \mu \mathrm{M}$ Mut 1; left, phase contrast; right, fluorescence mode (green channel, particles; red channel, glutaraldehyde). Scale bar, $50 \mu \mathrm{m}$. 
(a)

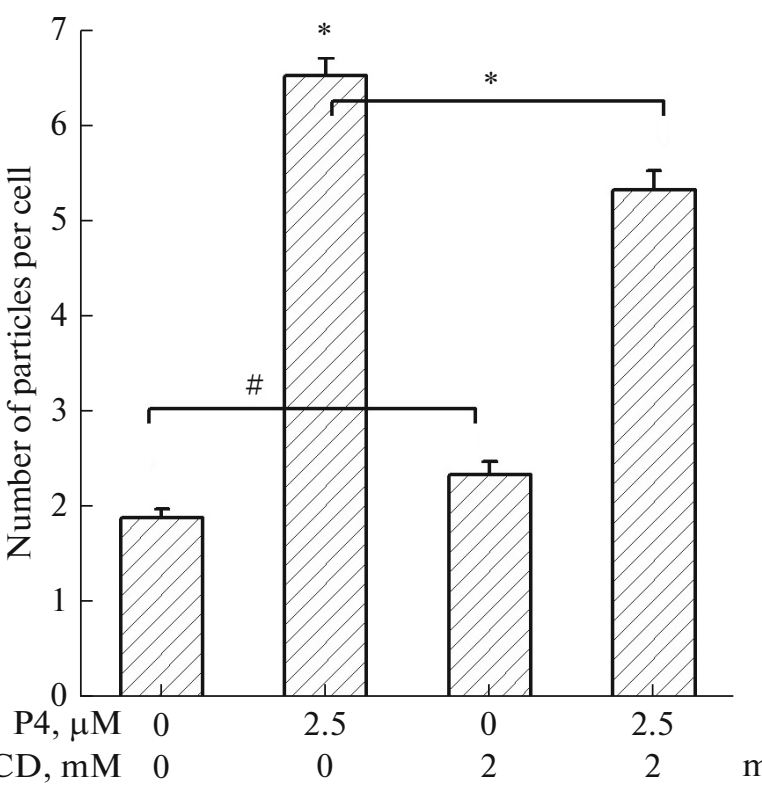

(c)

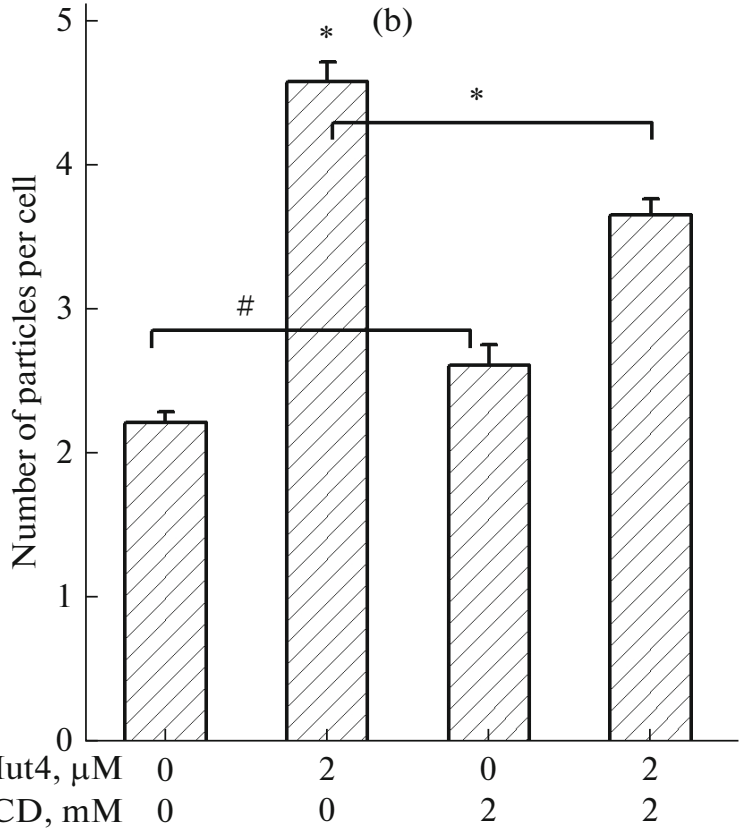

$\mathrm{m} \beta \mathrm{CD}, \mathrm{mM} \quad 0 \quad 00202$

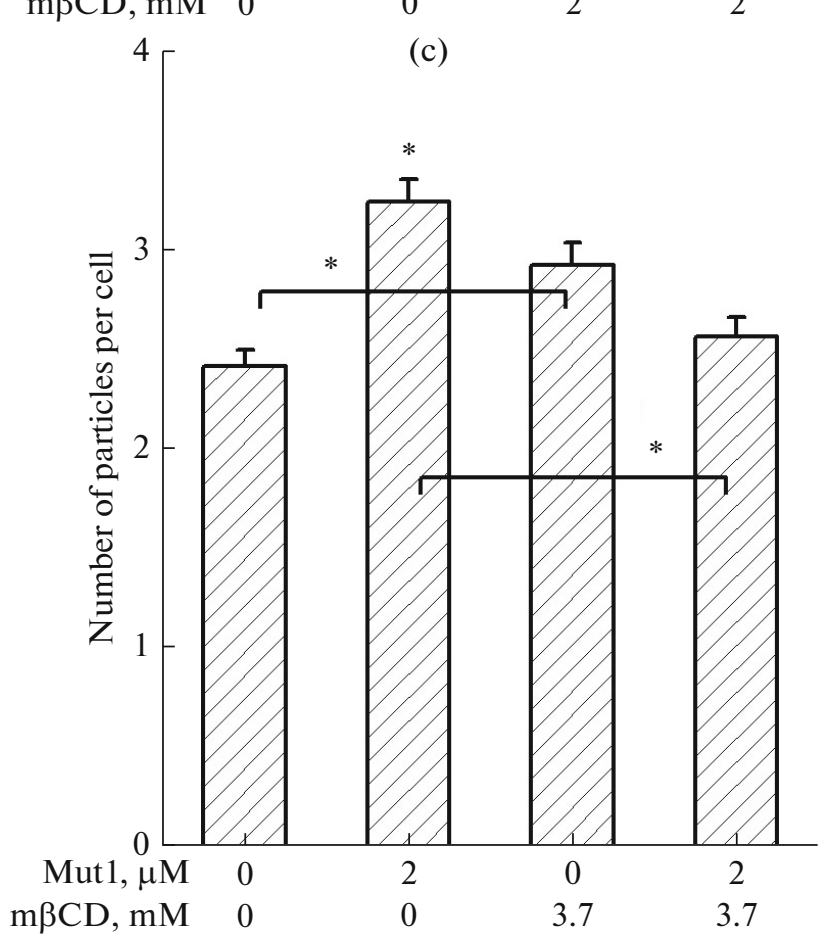

Fig. 5. Preliminary incubation of cells in the presence of methyl- $\beta$-cyclodextrin $(\mathrm{m} \beta C D)$ suppresses stimulating effect of peptides P4 (a), Mut4 (b), and Mut1 (c). In the absence of peptides, m $\beta C D$ at the used concentrations ( 2 or $3.7 \mathrm{mM})$ increases the cell activity. Representative experiments are given; each point is a mean number of particles per cell \pm SEM obtained for $\geq 200$ cells per well at a given peptide concentration; the difference from the control is significant by the Student's $t$-test at $p<0.001(*)$; differences between the groups shown by the square brackets are significant at $p<0.001(*)$ or $p<0.01(\#)$.

case of Mut1 (Fig. 5c), m $\beta C D$ also suppressed the stimulating effect of the peptide. In the experiment shown in Fig. 5c, in the absence of $m \beta C D$, the Mut 1 peptide at a concentration of $2 \mu \mathrm{M}$ stimulated the cell activity up to $134 \%$ of the control. In cells incubated in the presence of $3.7 \mathrm{mM} \mathrm{m} \beta \mathrm{CD}$ without a peptide, the activity was $121 \%$ of the control $(p<0.001)$. When
$2 \mu \mathrm{M}$ Mut 1 was added after the incubation of cells with $3.7 \mathrm{mM} \mathrm{m} \beta C D$, the cell activity was significantly lower (by $30 \%, p<0.001$ ) than in cells at the same peptide concentration in the absence of $\mathrm{m} \beta C D$. Overall, these results show that incubation of cells in the presence of cholesterol-extracting agent $\mathrm{m} \beta \mathrm{CD}$ at a concentration, at which the cell activity increases, 
leads to suppression of the stimulatory effects of peptides P4, Mut4, and Mut1. The suppression of cell activity in the presence of the peptide and $m \beta C D$ in stimulating concentrations indicates that the mechanisms of the effects of peptides and $\mathrm{m} \beta C D$ are interrelated; otherwise, the stimulating effects would have to add up. We suppose that the $\mathrm{m} \beta \mathrm{CD}$-induced modulation of the peptides' effects is associated with a change in the cholesterol concentration in the cell membranes.

\section{DISCUSSION}

In this work, we studied the role of CRAC motifs and motif-forming amino acids in the effects of peptide P4 (Ac-RTKLWEMLVELGNMDKAVKLWRKLKR- $\mathrm{NH}_{2}$ ) containing two cholesterol-recognizing motifs. We previously showed [28] that this peptide produces a dose-dependent effect on the activity of cultured IC-21 macrophages, evaluated by their ability to bind $2-\mu \mathrm{m}$ particles: at low concentrations (of the order of $1 \mu \mathrm{M}), \mathrm{P} 4$ exerted a stimulating effect on cells and was toxic at high concentrations $(50 \mu \mathrm{M})$ (Fig. 1, [28]). The results obtained in this work indicate that modifications of CRAC motifs in P4 significantly affect the ability of the peptide to modulate the activity of IC-21 cells. In particular, substitution of all motifforming amino acids $(\mathrm{V} \rightarrow \mathrm{S} ; \mathrm{W} \rightarrow \mathrm{S} ; \mathrm{R} / \mathrm{K} \rightarrow \mathrm{S})$ in $\mathrm{P} 4$ leads to a complete loss of the peptide activity: the mutant peptide Mut2 (Table 1), which differs from P4 only by these amino acids, did not alter the number of bound particles per cell (Figs. 2a, 2b; Table 2). Moreover, mutant peptide Mut3 with only tryptophan substitutions in CRAC motifs $(\mathrm{W} \rightarrow \mathrm{S}$ ) (Table 1) did not affect cell activity, either (Figs. 2c, 2d; Table 2). Interestingly, substitution of cationic amino acids only $(\mathrm{R} / \mathrm{K} \rightarrow \mathrm{S})$ in CRAC motifs had practically no effect on the activity of the peptide: the effects of mutant peptide Mut4 (Table 1), which differed from $\mathrm{P} 4$ only in these amino acids, were very similar to the effects of the "parental" peptide P4 (Fig. 3, Table 2). Finally, mutant peptide Mut1 (Table 1), consisting of the same amino acids as $\mathrm{P} 4$ but in a random order ("scramble"), and having one spontaneously generated CRAC motif different from the CRAC motifs of the P4 peptide, caused a moderate stimulation of the cells at slightly higher concentrations than P4 did and was not toxic at $50 \mu \mathrm{M}$ (Fig. 4, Table 2).

The preliminary incubation of cells in the presence of methyl- $\beta$-cyclodextrin extracting membrane cholesterol [37-39] led to the suppression of the stimulating effects of peptides Mut4 and Mut 1 at low concentrations (Figs. 5b, 5c), similar to what was observed in the case of peptide P4 ( Fig. 5a; [28]). As was noted above, the $\mathrm{m} \beta \mathrm{CD}$-induced inhibition of the peptide stimulating effect cannot be explained by the toxic effect of $m \beta C D$, since in our system $m \beta C D$ at concentrations below $5 \mathrm{mM}$ did not suppress but stimulated the cell activity (Fig. 5). We suppose that the cholesterol-dependent increase in cellular activity observed at low concentrations of CRAC-containing peptides P4, Mut4, and Mut1 can be explained by stimulation of the formation of cholesterol-enriched domains in the plasma membrane, which contributes to the aggregation of receptors responsible for the particle binding [32-36]. The weakening of stimulation and subsequent inhibition of the cell activity at higher peptide concentrations may be due to the competition of the CRAC peptide with cholesterol-dependent receptors for cholesterol, which leads to the receptor dysfunction [26]. At yet higher concentrations $(\sim 50 \mu \mathrm{M})$, peptides P4 and Mut4 containing two CRAC motifs become toxic (Figs. 1c, 3c). In [28] we suggested that the cholesterol-dependent toxic effect of P4 can be explained by the formation of transmembrane nonselective pores (for example, due to the oligomerization of peptide molecules), which should lead to leaks of intracellular contents and cell death; the same mechanism may work in the case of peptide Mut4. Perhaps peptide Mut1 with one CRAC motif is not able to form transmembrane pores. Short CRAC peptides VLNYYVW [29-31] and ATVLNYYVWRDNS [26] were not toxic at concentrations of the order of tens of $\mu \mathrm{M}$. Mechanisms of cytotoxicity of CRAC-containing peptides need further detailed investigations.

Our results are consistent with the data of other works, in which experimental modulation of cholesterol-dependent cellular processes using CRAC-containing peptides was carried out and the key role of CRAC-motifs in these effects was demonstrated [26, 42-46]. For example, Li et al. [26] showed that the intracellular delivery of the synthetic CRAC peptide ATVLNYYVWRDNS impairs cholesterol transport in mitochondria and leads to a dose-dependent inhibition of steroid hormone synthesis in Leydig cells; the peptide activity was lost upon substitution of the motif-forming amino acids.

A number of works emphasize the key role of aromatic amino acids in the CRAC motif; it can be either tyrosine or tryptophan or phenylalanine (see reviews $[24,25])$. Our data confirm that the presence of tryptophan in the CRAC motifs of the studied peptide P4 is critical for the activity of the peptide. The key role of tryptophan as a motive-forming aromatic amino acid of CRAC peptides has been shown in a number of works [45-47]. The significance of cationic amino acids in the cholesterol-dependent effect of the CRAC-containing peptide P4 in our experimental system is not so obvious and needs to be clarified. The mutant peptide Mut4 with substitutions of cationic amino acids in CRAC motifs was almost as active as P4 in respect of IC-21 cells (Fig. 3, Table 2). It was previously shown that peptide VLNYYVW, a fragment of a CRAC motif without a cationic amino acid, cholesterol-dependently modulates the activity of cultured macrophages IC-21 [29-31]. According to Azarashvili et al. [48], the same peptide prevents the opening of non-selective mitochondrial pores 
(mPTP) and the release of cytochrome $c$, as well as other apoptotic factors in mitochondria isolated from rat brain.

Peptide P4 used in our work was constructed on the basis of CRAC-containing $\alpha$-helices of the influenza virus M1 protein, and the fact that peptide P4 modulates the activity of macrophages indicates that similar modulations can also occur in the whole organism infected with the influenza virus. This implies that CRAC-containing peptides of viral origin can form the basis for the development of new drugs that regulate various vitally important cholesterol-dependent processes, among which interactions of cells with microbes play a significant role $[9,13-20]$. The possibility to influence the process of cell infection in vitro with a CRAC-containing peptide of viral origin was demonstrated by Cheng et al. [45]. The authors reported that peptide $\mathrm{C} 5 \mathrm{~A}$, containing amino acid residues 3-20 from the amphipathic $\alpha$-helical $\mathrm{N}$-terminal domain of the hepatitis C virus NS5A protein, suppressed virus production by more than 5 orders of magnitude. The authors did not mention the CRAC concept, although peptide C5A does possess the CRAC motif: SWLRDIWDWICEVLSDFK [45]. In 2018, the antiviral activity of the same C5A peptide against the human immunodeficiency virus HIV was demonstrated [46]. It is noteworthy that the so-called "aromatic domain" of the S-protein of SARS coronavirus [47] also contains CRAC motif (YIKWPWYVW) and that the infection with this coronavirus depends on cholesterol [49]. We suggest that the creation of CRAC-containing peptides that compete with the $\mathrm{S}$-protein for cholesterol and prevent the cell from being infected with coronavirus can be one of the ways to fight this infection. Moreover, the deteriorating effect of coronavirus upon its replication and the formation of the virion envelope from the host cell membrane may be similar to the toxic effect of high doses of some CRAC-containing peptides (Figs. 1c, 3c; [28]). The noxious impact of the CRAC-containing $\mathrm{S}$-protein of coronavirus inside the cell can be a direct result of the sequestration of cholesterol by S-protein and consequent malfunctioning of the cholesteroldependent proteins not only in the plasma membrane, but also in the membranes of intracellular organelles. Specially designed non-toxic CRAC-containing peptides may prevent this detrimental extraction of cholesterol by S-protein.

In conclusion, the results obtained in this work indicate that: (1) CRAC motifs play a significant role in the mechanism of effects induced by peptide P4 (RTKLWEMLVELGNMDKAVKLWRKLKR) containing two CRAC motifs; (2) of motif-forming amino acids, essential is the presence of aromatic amino acid tryptophan, the replacement of which with serine in both CRAC motifs inactivates the peptide; (3) the replacement of cationic amino acids (arginine and lysine) does not affect the studied effects of the peptide; (4) the presence of two CRAC motifs appears to be significant for the toxic effect of P4; (5) the effects of CRAC-containing peptides (P4, Mut4, and Mut1) depend on the cholesterol content in the membrane. The mechanisms of interactions of lipid and protein components of the cell membrane with CRAC-containing peptides that modulate cholesterol-dependent cellular functions, as well as the possibility of using such peptides for medical purposes, remains to be investigated.

\section{ACKNOWLEDGMENTS}

The authors thank L.A. Baratova and V.A. Radyukhin for a useful discussion of the project. This work was supported by the Russian Foundation for Basic Research (project no. 18-04-01363).

\section{COMPLIANCE WITH ETHICAL STANDARDS}

The authors declare that they have no conflict of interest.

This article does not contain any studies involving animals or human participants performed by any of the authors.

\section{REFERENCES}

1. Enkavi G., Javanainen M., Kulig W., Róg T., Vattulainen I. 2019. Multiscale simulations of biological membranes: The challenge to understand biological phenomena in a living substance. Chem. Rev. 119, 5607-5774.

2. Song Y., Kenworthy A.K., Sanders Ch.R. 2014. Cholesterol as a co-solvent and a ligand for membrane proteins. Protein Science. 23, 1-22.

3. Ikonen E. 2008. Cellular cholesterol trafficking and compartmentalization. Nat. Rev. Mol. Cell Biol. 9 (2), $125-138$. https://doi.org/10.1038/nrm2336

4. Muller M.P., Jiang T., Sun C., Lihan M., Pant S., Mahinthichaichan P., Trifan A., Tajkhorshid E. 2019. Characterization of lipid-protein interactions and lipid-mediated modulation of membrane protein function through molecular simulation. Chem. Rev. 119 (9), 6086-6161. https://doi.org/10.1021/acs.chemrev.8b00608

5. Kiriakidi S., Kolocouris A., Liapakis G., Ikram S., Durdagi S., Mavromoustakos Th. 2019. Effects of cholesterol on GPCR function: Insights from computational and experimental studies. In: Direct mechanisms in cholesterol modulation of protein function. Eds Rosenhouse-Dantsker A., Bukiya A.N. Series Advances in experimental medicine and biology, vol. 1135. Cham: Springer, p. 89-103.

https://doi.org/10.1007/978-3-030-14265-0_5

6. Lundbæk J.A., Birn P., Hansen A.J., Søgaard R., Nielsen C., Girshman J., Bruno M.J., Tape S.E., Egebjerg J., Greathouse D.V., Mattice G.L., Koeppe R.E. II, Andersen O.S. 2004. Regulation of sodium channel function by bilayer elasticity: The importance of hydrophobic coupling. Effects of micelle-forming amphiphiles and cholesterol. J. Gen. Physiol. 123, 599-621. 
7. Resnik N., de Luca G.M.R., Sepčić K., Romih R., Manders E., Veranič P. 2019. Depletion of the cellular cholesterol content reduces the dynamics of desmosomal cadherins and interferes with desmosomal strength. Histochem. Cell Biol. 152 (3), 195-206. https://doi.org/10.1007/s00418-019-01797-1

8. Tabas I. 2010. Macrophage death and defective inflammation resolution in atherosclerosis. Nat. Rev. Immunol. 10 (1), 36-46.

https://doi.org/10.1038/nri2675

9. Sviridov D., Mukhamedova N., Makarov A.A., Adzhubei A., Bukrinsky M. 2020. Comorbidities of HIV infection: Role of Nef-induced impairment of cholesterol metabolism and lipid raft functionality. AIDS. 34, 1-13.

10. Tang Q., Wang F., Yang J., Peng H., Li Y., Li B., Wang S. 2020. Revealing a novel landscape of the association between blood lipid levels and Alzheimer's disease: A meta-analysis of a case-control study. Front. Aging Neurosci. 11, 370 .

https://doi.org/10.3389/fnagi.2019.00370

11. Singhal A., Szente L., Hildreth J.E.K., Song B. 2018. Hydroxypropyl-beta and -gamma cyclodextrins rescue cholesterol accumulation in Niemann-Pick C1 mutant cell via lysosome-associated membrane protein 1. Cell Death Dis. 9 (10), 1019. https://doi.org/10.1038/s41419-018-1056-1

12. Shi L., Huang L., He R., Huang W., Wang H., Lai X., Zou Z., Sun J., Ke Q., Zheng M., Lu X., Pei Z., Su H., Xiang A.P., Li W., Yao X. 2018. Modeling the pathogenesis of Charcot-Marie-Tooth disease type 1A using patient-specific iPSCs. Stem Cell Reports. 10 (1), $120-133$. https://doi.org/10.1016/j.stemcr.2017.11.013

13. Nayak D.P., Hui E.K. 2004. The role of lipid microdomains in virus biology. Subcell Biochemistry. 37, 443-491.

14. Carter G.C., Bernstone L., Sangani D., Bee J.W., Harder T., James W. 2009. HIV entry in macrophages is dependent on intact lipid rafts. Virology. 386, 192202.

15. Dou X., Li Y., Han J., Zarlenga D.S., Zhu W., Ren X., Dong N., Li. X., Li G. 2018. Cholesterol of lipid rafts is a key determinant for entry and post-entry control of porcine rotavirus infection, BMC Vet. Res. 14 (1), 45. https://doi.org/10.1186/s12917-018-1366-7

16. Lafont F., van der Goot F.G. 2005. Bacterial invasion via lipid rafts. Cellular Microbiol. 7 (5), 613-620. https://doi.org/10.1111/j.1462-5822.2005.00515.x

17. Gatfield J., Pieters J. 2000. Essential role for cholesterol in entry of mycobacteria into macrophages. Science. 288, 1647-1650.

18. Ouellet H., Johnston J.B., Ortiz de Montellano P.R. 2011. Cholesterol catabolism as a therapeutic target in Mycobacterium tuberculosis. Trends Microbiol. 19 (11), 530-539.

19. Viswanathan G., Jafurulla M., Kumar G.A., Raghunand T.R., Chattopadhyay A. 2015. Dissecting the membrane cholesterol requirement for mycobacterial entry into host cells. Chemistry and Physics of Lipids. 189, 19-27.

20. Peyron P., Bordier C., N'Diaye E.-N., MaridonneauParini I. 2000. Nonopsonic phagocytosis of Mycobacte- rium kansasii by human neutrophils depends on cholesterol and is mediated by CR3 associated with glycosylphosphatidylinositol-anchored proteins. J. Immunol. 165, 5186-5191.

21. Sezgin E., Levental I., Mayor S., Eggeling C. 2017. The mystery of membrane organization: Composition, regulation and roles of lipid rafts. Nat. Rev. Mol. Cell Biol. 18, 361-374.

22. Li H., Papadopoulos V. 1998. Peripheral-type benzodiazepine receptor function in cholesterol transport. Identification of a putative cholesterol recognition/interaction amino acid sequence and consensus pattern. Endocrinol. 139, 4991-4997

23. Papadopoulos V., Baraldi M., Guilarte T.R., Knudsen T.B., Lacapere J.J., Lindemann P.L., Norenberg M.D., Nutt D., Weizman A., Zhang M.R., Gavish M. 2006. Translocator protein $(18 \mathrm{kDa})$ : New nomenclature for the peripheral-type benzodiazepine receptor based on its structure and molecular function. Trends Pharmacol. Sci. 27, 402-409.

24. Fantini J., Epand R.M., Barrantes F. J. 2019. Cholesterol-recognition motifs in membrane proteins. In: $D i-$ rect mechanisms in cholesterol modulation of protein function. Eds Rosenhouse-Dantsker A., Bukiya A.N. Series Advances in experimental medicine and biology, vol. 1135. Cham: Springer, p. 3-25. https://doi.org/10.1007/978-3-030-14265-0_1

25. Miller C.M., Brown A.C., Mittal J. 2014. Disorder in cholesterol-binding functionality of CRAC peptides: A molecular dynamics study. J. Phys. Chem. B. 118, 13169-13174.

26. Li H., Yao Z., Degenhardt B., Teper G., Papadopoulos V. 2001. Cholesterol binding at the cholesterol recognition/interaction amino acid consensus (CRAC) of the peripheral-type benzodiazepine receptor and inhibition of steroidogenesis by an HIV TAT-CRAC peptide. Proc. Natl. Acad. Sci. USA. 98 (3), 1267-1272.

27. Dunina-Barkovskaya A.Ya., Vishnyakova Kh.S., Golovko A.O., Arutyunyan A.M., Baratova L.A., Batishchev O.V., Radyukhin V.A. 2018. Amphipathic CRAC-containing peptides derived from the influenza virus A M1 protein modulate cholesterol-dependent activity of cultured IC-21 macrophages. Biochemistry (Moscow). 83, 982-991.

28. Dunina-Barkovskaya A.Ya., Vishnyakova Kh.S., Baratova L.A., Radyukhin V.A. 2019. Modulation of cholesterol-dependent activity of macrophages IC-21 by a peptide containing two CRAC motifs from protein M1 of influenza virus. Biochemistry (Moscow), Suppl. Series A: Membr. Cell Biol. 13 (3), 268-276.

29. Dunina-Barkovskaya A.Ya., Vishnyakova H.S., Cheshev D.A., Chekanov N.N., Buzhurina I.M. 2006. Effects of DMSO and cholesterol-binding peptides on phagocytic activity of cultured macrophages IC-21. Biol. Membranes (Rus.). 24, 451-456.

30. Golovkina M.S., Skachkov I.V., Metelev M.V., Kuzevanov A.V., Vishnyakova H.S., Kireev I.I., Dunina-Barkovskaya A.Ya. 2009. Serum-induced inhibition of the phagocytic activity of cultured macrophages IC-21. Biochemistry (Moscow) Suppl. Ser. A: Membr. Cell Biol. 3, 412-419.

31. Vishnyakova Kh.S., Kireev I.I., Dunina-Barkovskaya A.Ya. 2011. Effects of cell culture density on 
phagocytosis parameters. Biochemistry (Moscow) Suppl. Series A: Membr. Cell Biol. 5 (4), 355-363.

32. Ueda M.J., Ito T., Ohnishi S., Okada T.S. 1981. Phagocytosis by macrophages. I. Kinetics of adhesion between particles and phagocytes. J. Cell Sci. 51, 173-188.

33. Han J., Hajjar D.P., Tauras J.M., Nicholson A.C. 1999. Cellular cholesterol regulates expression of the macrophage type B scavenger receptor, CD36. J. Lipid. Res. 40, 830-838.

34. Febbraio M., Hajjar D.P., Silverstein R.L. 2001. CD36: A class B scavenger receptor involved in angiogenesis, atherosclerosis, inflammation, and lipid metabolism. J. Clin. Invest. 108, 785-791. https://doi.org/10.1172/JCI200114006

35. Dunina-Barkovskaya A.Ya. 2004. Phagocytosis - three in one: Endocytosis, exocytosis, and adhesion. Biol. Membranes (Rus.). 21, 243-270.

36. Oh H., Mohler E.R., Tian A., Baumgart T., Diamond S.L. 2009. Membrane cholesterol is a biomechanical regulator of neutrophil adhesion. Arterioscler. Thromb. Vasc. Biol. 29, 1290-1297.

37. Zidovetzki R., Levitan I. 2007. Use of cyclodextrins to manipulate plasma membrane cholesterol content: Evidence, misconceptions and control strategies. Biochim. Biophys. Acta, Biomembranes. 1768, 1311-1324.

38. Kurkov S.V., Loftsson Th. 2013. Cyclodextrins. Int. J. Pharmaceutics. 453, 167-180.

39. Leclercq L. 2016. Interactions between cyclodextrins and cellular components: Towards greener medical applications? Beilstein J. Org. Chem. 12, 2644-2662.

40. Pike L.J., Miller J.M. 1998. Cholesterol depletion delocalizes phosphatidylinositol bisphosphate and inhibits hormone-stimulated phosphatidylinositol turnover. J. Biol. Chem. 273, 22298-22304.

41. Kumar G.A., Roy S., Jafurulla M., Mandal C., Chattopadhyay A. 2016. Statin-induced chronic cholesterol depletion inhibits Leishmania donovani infection: Relevance of optimum host membrane cholesterol. Biochim. Biophys. Acta. 1858 (9), 2088-2096. https://doi.org/10.1016/j.bbamem.2016.06.010

42. Koufos E., Chang E.H., Rasti E.S., Krueger E., Brown A.C. 2016. Use of a cholesterol recognition amino acid consensus peptide to inhibit binding of a bacterial toxin to cholesterol. Biochemistry. 55 (34), 4787-4797.
43. Rout A.K., Wu X., Starich M.R., Strub M.-P., Hammer J.A., Tjandra N. 2018. The structure of melanoregulin reveals a role for cholesterol recognition in the protein's ability to promote dynein function. Structure. 26 (10), 1373-1383.

https://doi.org/10.1016/j.str.2018.07.009

44. Brown A.C., Balashova N.V., Epand R.M., Epand R.F., Bragin A., Kachlany S.C., Walters M.J., Du Y., Boesze-Battaglia K., Lally E.T. 2013. Aggregatibacter actinomycetemcomitans leukotoxin utilizes a cholesterol recognition/amino acid consensus site for membrane association. J. Biol. Chem. 288 (32), 23607-23621. https://doi.org/10.1074/jbc.M113.486654

45. Cheng G., Montero A., Gastaminza P., Whitten-Bauer C., Wieland S.F., Isogawa M., Fredericksen B., Selvarajah S., Gallay P.A., Ghadiri M.R., Chisari F.V. 2008. A virocidal amphipathic $\alpha$-helical peptide that inhibits hepatitis $\mathrm{C}$ virus infection in vitro. Proc. Natl. Acad. Sci. USA. 105, 3088-3093.

https://doi.org/10.1073/pnas.0712380105

46. Gallay P.A., Chatterji U., Kirchhoff A., Gandarilla A., Pyles R.B., Baum M.M., Moss J.A. 2018. Protection efficacy of C5A against vaginal and rectal HIV challenges in humanized mice. Open Virol. J. 12, 1-13. https://doi.org/10.2174/1874357901812010001

47. Corver J., Broer R., van Kasteren P., Spaan W. 2009. Mutagenesis of the transmembrane domain of the SARS coronavirus spike glycoprotein: Refinement of the requirements for SARS coronavirus cell entry. Virol. J. 6, 230 . https://doi.org/10.1186/1743-422X-6-230

48. Azarashvili T., Krestinina O., Baburina Y., Odinokova I., Akatov V., Beletsky I., Lemasters J., Papadopoulos V. 2016. Effect of the CRAC peptide, VLNYYVW, on mPTP opening in rat brain and liver mitochondria. Int. J. Mol. Sci. 17 (12). pii: E2096.

49. Glende J., Schwegmann-Wessels C., Al-Falah M., Pfefferle S., Qu X., Deng H., Drosten C., Naim H.Y., Herrler G. 2008. Importance of cholesterol-rich membrane microdomains in the interaction of the $\mathrm{S}$ protein of SARS-coronavirus with the cellular receptor angiotensin-converting enzyme 2. Virology. 381 (2), 215221.

https://doi.org/10.1016/j.virol.2008.08.026

Translated by A. Dunina-Barkovskaya 